Int. J. Electrochem. Sci., 12 (2017) 9040 - 9050

\title{
Preparation of Metal Nanoparticles by Jet Electrodeposition Using Monocrystalline Silicon Substrate
}

\author{
Lida Shen ${ }^{l, *}$, Wei Zhuo ${ }^{l}$, Mingbo Qiu, Zongjun Tian, Chuan Wang \\ College of Mechanical and Electrical Engineering, Nanjing University of Aeronautics and \\ Astronautics, Nanjing, 210016 \\ ${ }^{1}$ These authors contributed equally to this work \\ *E-mail: 1dshen@nuaa.edu.cn
}

doi: $10.20964 / 2017.10 .87$

Received: 5 July 2017 / Accepted: 18 August 2017 / Published: 12 September 2017

\begin{abstract}
This study proposes a method for rapid preparation of nanoparticles (NPs) by jet electrodeposition on silicon substrate. Micropyramidal structures were formed on a specific crystallographic plane of monocrystalline silicon substrate after polishing and alkali treatment. With cathode translational motion and high current density, jet electrodeposition discharged metal ions into atoms that rapidly assembled at the tip of silicon micropyramids to form nuclei and generate NPs. The effects of surface roughness, current density, and cathode translational speed on NP size and distribution uniformity were investigated by using copper NPs as the research object. NP size distribution rules for different parameters were obtained by the field emission scanning electron microscopic image analysis and optimized process parameters. Results showed that low silicon substrate roughness was favored preparation of copper NPs with good size refinement and uniform size distribution. Moreover, these NPs exhibited desirable refinement and uniformity when the current density was $200 \mathrm{~A} / \mathrm{dm}^{2}$ and cathode translational speed $480 \mathrm{~mm} / \mathrm{min}$.
\end{abstract}

Keywords: jet electrodeposition; nanoparticles; surface roughness; current density; cathode translational speed

\section{FULL TEXT}

(C) 2017 The Authors. Published by ESG (www.electrochemsci.org). This article is an open access article distributed under the terms and conditions of the Creative Commons Attribution license (http://creativecommons.org/licenses/by/4.0/). 